\title{
José Martí y la expresión paralela de prosa y verso
}

En el estudio de Martí poeta tal vez no reciba el crítico una impresión más profunda y permanente que la de su honda raíz vital. ${ }^{1}$ En realidad todo su canto es un manar de vida y, por consiguiente, toda su vida un hontanar de versos. El hombre se descubre siempre tras el bardo; la existencia se evidencia indefectiblemente tras el canto. En los primeros tiempos -Ismaelillo, Versos libres (1882) - predomina un mayor ambiente de irrealidad poética, aunque sean objeto de inspiración el hijo y el choque del ensueño con la realidad hiriente. Pero en los Versos sencillos (1891) lo vivido se diluye apenas conservándose en concreción tal de acontecimientos personales que un número considerable de poemas responde a situaciones bien conocidas de la vida del autor. A veces las raíces llegan tan a lo hondo que, ignorantes de ciertos detalles biográficos, perdemos contacto con el hombre para quedarnos sólo ante la esfinge. $Y$ sin embargo, el motivo vital parece estar siempre presente, véamoslo o no, germen creador y de luz. El mismo Martí nos lo dice en más de una ocasión. En esa biografía poética final de los Versos sencillos, paralela a la humana del comienzo, exclama:

Yo te quiero, verso amigo,

Porque cuando siento el pecho

1 "...en nadie ha sido la vida como en él, substancia poética de posibilidades preciosas en la transfiguración que es siempre el poema auténtico", Concha Meléndez, "El crecer de la poesía de Marti", Asomante, 3 (1953), 29. 
Ya muy cargado $\mathrm{y}$ ' deshecho,

Parto la carga contigo. 2

$Y$ en carta a la madre, al mencionar el ejemplar de su obra que le envía, dice:

Lea ese libro de versos... Es pequeño-es mi vida. II, $1801)^{3}$

Como consecuencia natural de esa actitud son muy significativos aquellos versos iniciales de doble localización moral y espacial :

Yo soy un hombre sincero

De donde crece la palma, (II, 1351).

porque en ellos surge, desde las primeras palabras, el hombre íntegro, de alma desnuda, como on una magnífica llamarada súbita.

Bien se deduce que quien estudie los Versos sencillos sin la antorcha de su vida y de su propia - prosa íntima y públicaes náufrago de la niebla. Al Martí de los Versos sencillos lo complementa el Martí de la prosa. Su epistolario, sus piezas oratorias, sus trabajos periodísticos, y en general toda su obra, constituyen una mina exegética de inapreciable valor. En oca. siones se advierte, sencillamente, la persistencia de una idea: otras veces se revela la noticia biográfica necesaria para la comprensión cabal de un poema; y hasta casos hay en los que se puede seguir el desarrollo de una imagen imprescindible para la interpretación acabada de la composición. Mas, en una forma

2 Obras completas, La Habana, Editorial Lex, 1946, II, 1363. Las citas que siguen son de la misma edición.

3 En el prólogo de Ismaelillo, dedicado al hijo, escribe:

Tal como aquí te pinto, tal te han visto mis ojos. ... Cuando he cesado de verte en esa forma, he cesado de pintarte. Esos riachuelos han pasado por mi corazón. (II, 1340).

$Y$ en el de los Versos libres:

Tajos son éstos de mis propias entrañas-mis guerreros-. Ninguno me ha salido recalentado, artificioso, recompuesto, de la mente; sino como las lágrimas salen de los ojos y la sangre sale a borbotones de la herida.

No zurcí de éste y aquél, sino sajé en mí mismo. Van escritos, no en tinta de academia, sino en mi propia sangre. (II, 1364). 
u otra, puede sentir el lector la presencia de un girón emotivo arrancado a la vida.

Entre los muchos casos que podrían citarse de la más simple, aunque invariablemente, estrecha, correspondencia de prosa y verso, recordemos algunos ejemplos significativos:

... los horribles días de Enero que llenaron de cadáveres asesinados la calzada de Jesús del Monte y las calles de Jesús María y los que mi madre atravesó para buscarme, y pasando a su lado las balas, y cayendo a su lado los muertos... Era mi madre: fue a buscarme en medio de la gente herida, $y$ las calles cruzadas a balazos, $y$ sobre su cabeza misma clavadas las balas que disparaban a una mujer, allí en el lugar aquel donde su inmenso amor pensó encontrarme. [1875] $(I, 62)$.

El hombre íntimo está muerto y fuera de toda resurrección, que sería el hogar franco y para mí imposible, adonde está la única dicha humana, o la raíz de todas las dichas. Pero el hombre vigilante y compasivo está aún vivo en mí, como un esqueleto que se hubiese salido de su sepultura; y sé que no le esperan más que ccrmbates y dolores en la contienda de los hombres... [1894] (II, 1802).
El enemigo brutal

Nos pone fuego a la casa:

El sable la calle arrasa

A la luna tropical.

Pocos salieron ilesos

Del sable del español:

La calle, al salir el sol, Era un reguero de sesos. Pasa, entre balas, un coche:

Entran, llorando a una muerta:

Llama una mano a la puerta

En lo negro de la noche

No hay bala que no taladre

El portón: y la mujer

Que llama, me ha dado el ser:

Me viene a buscar mi madre.

(II, 1359)

Yo tengo un amigo muerto que suele venirme a ver:

Mi amigo se sienta, y canta:

Canta en voz que ha de doler...

"El corazón es un loco

"Que no sabe de un color:

"O es su amor de dos colores,

"O dice que no es amor...

"Corazón que lleva rota

"El ancla fiel del hogar,

"Va como barca perdida,

"Que no sabe a dónde va".

En cuanto llega a esta angustia

Rompe el muerto a maldecir:

Le amanso el cráneo: lo acuesto:

Acuesto el muerto a dormir.

(II, 1354)

En mí hay una especie de asesi. nado, y no diré yoo quién sea el asesino. [1883] (II, 1806).
Yo que vivo, aunque me he muerto, ...

(II, 1358) 
"... yo no hablo de mis penas personales, porque aunque me han dado la puñalada de muerie, no pienso en ellas. ... Lo que casi me ha sacado la tierra de los pies es el peligro en que veo a mi tierra..." [1889] (II, 890).

Todo tiene la entraña fea y san. grienta: es fango en las artesas el oro que el artista talla luego sus joyas maravillosas; de lo fétido de la vida saca almíbar la fruta y colores la flor; nace el hombre del dolor y la tiniebla del seno mater. nal... [1891] (I, 702).

Otros lamenten la muerte necesaria: yo creo en ella como la almohada y la levadura, y el triunfo de la vida... La amapola roja y más leve crece sobre las tumbas desatendidas. El árbol que da mejor fruta es el que tiene debajo un muerto. [1891] (I, 37-38).

¡Allá está, [Cuba] herida en la frente, herida en el corazón, presidiendo, atada a la silla de tortura, el banquete adonde las bocamangas de galón de oro ponen el vino del veneno en los labios de los hijos que se han olvidado de sus padres! i $\mathrm{Y}$ el padre murió cara a cara al alférez, y el hijo va, de brazos con el alférez, a podrirse a la orgía! [1891] (I, 706).
He visto vivir a un hombre Con el puñal al costado, Sin decir jamás el nombre De aquella que lo ha matado

¡Penas! ¿Quién osa decir (II, 1315 $)^{4}$

Que tengo yo penas? Luego, Después del rayo, y del fuego, Tendré tiempo de sufrir.

(II, 1360)

Todo es hermoso y constante, Todo es música y razón. $\mathrm{Y}$ todo, como el diamante, Antes que luz es carbón.5

(II, 1351)

Yo sé que el necio se entierra Con gran lujo y con gran llanto, $X$ que no hay fruta en la tierra Como la del camposanto.

(II, 1352)

Por la tumba del cortijo Donde está el padre enterrado, Pasa el hijo, de soldado Del invasor: pasa el hijo. El padre, un bravo en la guerra, Envuelto en su pabellón Alzase: y de un bofetón Lo tiende, muerto, por tierra.

(II, 1359)

Dicen que beben tus hijos

Su propia sangre en las copas

4 Para el motivo del puñal recuérdese también la composición XXXV.

5 En los Versos libres había expresado asi esta idea:

Naturaleza, siempre viva; el mundo

De minotauro yendo a mariposa. (II, 1386). 
Venenosas de sus dueños! ... iQue comen

Juntos el pan del oprobio,

En la mesa ensangrentada!

(II, 1363)

$i$... el hijo que tengo, si me le falla a su país, o me lo engaña u oscurece, ni es mi hijo, ni lo defiendo contra mi patria. [1894] (T. 220).
Para modelo de un dios El pintor lo envió a pedir: ¿Para eso no! ipara ir, Patria, a servirte los dos!... Vamos, pues, hijo viril: Vamos los dos: si yo muero, Me besas: si tú... iprefiero Verte muerto a verte vil!

(II, 1360)

Si en fragmentos como los anteriores se advierte, en forma más o menos acentuada, un indudable paralelismo de ideas, imágenes o temas, no siempre puede verse en ellos ejemplos de evolución, y culminación, de un tema poético. Los más son casos de honda reacción emotiva expresada primero en prosa y luego en verso, o viceversa. Aunque hay también recuento de lo vivido o sentido. Pero en otras ocasiones semejantes correspondencias parecen ser la elaboración de una idea que llega, finalmente al verso. Con aquella angustia tan suya por las impurezas y sordideces que se veía obligado a presenciar y a sufrir le escribía Martí a Manuel Mercado en 1886:

Yo estoy, mire que así me siento, como una cierva acorralada por los cazadores en el último hueco de la caverna. Si no cae sobre mi alma algún gran quehacer que me la ocupe y redima, y alguna gran lluvia de amor, yo me veo por dentro, y sé que muero. (II, 862).

El mismo año añadía:

Mi consulado, que me venía ayudando, se me acaba el mes próximo. Si no me saca V. por sobre su cabeza en esto de los diarios, tendré de nuevo — sin que nadie, eso sí, note mi desfallecimiento- que acudir a una colocación vulgar de comercio, de muchas horas y retribución mezquina, a donde vuelva mi vida a lo que ha sido en estos tiempos últimos, avena de pesebre, a que se la coman los caballos. Lo que me entristece no es sino que en esa profesión, 
como acá se ejerce, y en la condición ruin de empleado menor en que tendría yo que volver a ejercerla, cada detalle ¿por qué no decirlo? me subleva $y$ aturde, $y$ vivo como acorralado y apaleado, y la brutalidad, deshonestidad y sordidez que veo a mi alrededor y de que tengo que ser instrumento me imponen, -creo que ya se lo he dicho a $\mathrm{V}$. porque es verdad - como una cierva, despedazada por las mordidas de los perros, que se refugia para morir en el último tronco. ...Trabaje por mí, que esta alma mía no se ha hecho para extinguirse tan a oscuras $y$ por tan pobres razones. (II, 864-865).

Ignorado por el materialismo y la incomprensión que lo rodean la imagen tenaz de la cierva acorralada se combina aquí con la agonía creciente de pasar por la vida sin hacer obra grande. En cuanto al tema inicial, de la prosa íntima salta a la pública. Y un año más tarde, en artículo para La Nación, se expresaria así:

El alma, es verdad, va por la vida como en la cacería la cierva acorralada, sin tiempo para despuntar los retoños jugosos, o aspirar el aire vivífico, o aquietar la sed en aquel arroyuelo del bosque... En cuanto el alma asoma, un escopetazo la echa abajo: para vivir, hay que esconderla donde no nos la sospechen, y en las horas de soledad, en las horas de lujo, sacarla a la luz tenue, como el relicario que guarda la efigie de la mujer querida, y llorar sobre ella, acariciarle la cabellera pegada a las sienes, aquietarle la mirada ansiosa, y decirle con la voz de los desesperados: “¿cuándo acabaremos, oh alma?" (I, 1016).

En todo esto está ya como madura, con la emoción hecha palabra, la materia poética. Al verso llega, lógicamente, en expresión estilizada y precisa:

Yo sé de un gamo aterrado

Que vuelve al redil, 5 expira,-

$\mathrm{Y}$ de un corazón cansado

Que muere oscuro y sin ira. (II, 1352) ${ }^{6}$

6 La oscuridad del talento desconocido, obligado a menesteres ruines, es en Martí tema frecuente y halla también forma en la poesía XXIV. Tanto éste como el de la cierva acorralada aparecen con frecuencia en los Versos libres. Recuérdense, entre otras, las composiciones tituladas "Media Noche", "Homagno", "Aguila blanca" y "A los espacios". 
¡Cuánto dolorido vivir, y pensar, tras esa pequeñez de cuatro versos!

Semejante itinerario puede trazarse en cuanto al panteísmo, a veces cristiano, del autor. En su artículo sobre "Emerson" (1882) surge en prosa de homenaje emocionado:

Para él no hay cirios como los astros, ni altares como los montes, ni predicadores como las noches palpitantes y profundas. (I, 1056).

Dos años después repite conceptos semejantes sobre el poeta y orador uruguayo Juan Carlos Gómez:

Para él no hubo más ejemplo digno de ver de rodillas al hombre que la Naturaleza; y vivió comido de sueños del Cielo y amores humanos. (II, 38).

$\mathrm{Y}$ en 1887 reaparece en su comprensivo estudio de Walt Whitman:

Mide las religiones sin ira; pero cree que la religión perfecta está en la Naturaleza. La religión y la vida están en la Naturaleza. (I, 1139).

De idéntico molde ideológico sale esta brillante descripción del templo de la naturaleza:

Busca el obispo de España

Pilares para su altar;

¡En mi templo, en la montaña,

El álamo es el pilar!

Y la alfombra es puro helecho,

$\mathrm{Y}$ los muros abedul,

Y la luz viene del techo,

Del techo de cielo azul.

Brillan las grandes molduras

Al fuego de la mañana,

Que tiñe las colgaduras

De rosa, violeta y grana.

¡Díganle al obispo ciego,

al viejo abispo de España

Que venga, que venga luego,

A mi templo, a la montaña! (Ir, 1352) 
Semejante panteísmo representa en esta poesía una porción notable de su sentido general de identificación con los aspectos más puros, menos adulterados, del universo. Pero en la siguiente, limitado su sentido de pureza al tema del amor, aparece en la delicáa expresión de la mujer ideal, refinada y sensible, que evoca el poeta:

\author{
"Nunca más altos he visto \\ Estos nobles robledales: \\ Aquí debe estar el Cristo, \\ Porque están las catedrales". \\ "Ya sé dónde ha de venir \\ Mi niña a la comunión; \\ De blanco la he de vestir \\ Con un gran sombrero alón". (II, 1353)?
}

De las composiciones que aparecen en los Versos sencillos ninguna posee acaso un mayor caudal aclarativo, o simplemente paralelo, en prosa, que "los hombres de mármol" (XLV). En estilo muy similar al con frecuencia alucinado de los Versos $l i$ bres, se utiliza el tema de estatuas que reaccionan con ira ante quienes insinúan la muerte del espíritu heroico:

$$
\begin{aligned}
& \text { Sueño con claustros de mármol } \\
& \text { Donde en silencio divino }
\end{aligned}
$$

7 Los antecedeates más lejanos de estas composiciones están probablemente en las enseñanzas del gran maestro de Martí, Rafael Mendive, cuya "Oración de la tarde", de 1854, ofrece interesantes semejanzas:

\footnotetext{
Alcemos nuestro templo en la montaña,

Teniendo por techumbre el ancho cielo,

Por luz la estrella, por alfombra el suelo,

$Y$ un árbol por altar.

El ámbar de la flor será el incienso,

$Y$ el suspiro del viento en lejanía

La plegaria de paz que a Dios envía

Contrito corazón.

Del órgano sagrado el grave coro

Ia música será de los torrentes,

$\mathrm{Y}$ el canto de las aves inocentes

La mística oración.
}

Poesias de D. Rafael Mendive, Madrid, M. Rivadeneyra, 1860, 70. 
Los héroes, de pie, reposan:

$$
\text { ... [ [Dicen, }
$$

Oh mármol, mármol dormido, Que ya se ha muerto tu raza!" Echame en tierra de un bote El héroe que abrazo: me ase Del cuello: barre la tierra Con mi cabeza: levanta El brazo, el brazo le luce Lo mismo que un sol!: resuena La piedra: buscan el cinto Las manos blancas: del soclo Saltan los hombre de mármol! (II, 1362-1363)

Aunque fácilmente puede captarse el sentido general del poema es muy probable que con frecuencia escape el más personal que le da la expresión clave "hombres de mármol". Y con ello toda la realidad, la emoción y la angustia patrióticas que dan origen a la composición. Es decir, su más cabal sen. tido poético. El ritmo entrecortado, expresivo del ansia, la pasión y el miedo que crean esos versos es, sin duda, parte muy fundamental de su sentido y emotividad; y tanto el uno como la otra provienen, precisamente, de la profunda significación humana e histórica que para el poeta tiene la imagen original.

En la obra de Martí es siempre bien evidente la importancia del culto heroico para la supervivencia de toda nacionalidad. "Honrar héroes, los hace", (I, 1523) había dicho, y también: "Se afirma un pueblo que honra a sus héroes". (II, 43) Para la Cuba de entonces, nacionalidad aún no devenida estado, pero con la urgencia irrefrenable de su evolución hacia esa meta, la necesidad de tal culto adquiere proporciones dramáticas, incrementadas por indiferencias, rivalidades y ambiciones inconfesables. El poeta, visión, ejemplo y prédica, no puede ser sino una llama enhiesta de agonía y deber. Sin tregua actúa, habla y escribe. Por eso los varios y dispersos elementos que crean la imagen y la idea de los "hombres de mármol" se pueden encontrar con significativa frecuencia por la época en que van a concebirse, y aparecer, los Versos sencillos, entre los años 1888 y 1892.

El vocablo "mármol" lo usa Martí algunas veces como 
sinónimo de riqueza y posición social; por lo que refiriéndose a los iniciadores de la Guerra de los Diez Años (1868-1878) - terratenientes y hombres adinerados en su mayoría- lo emplea en más de una ocasión:

... a los lindoros que desdeñan hoy esta revolución santa cuyos guías y mártires primeros fueron hombres nacidos en el mármol $y^{\prime}$ seda de la fortuna... [1891] (I, 705).

¿Uno es, pues, en los que pisan el mármol y los que pisan el tablado, aquel espíritu de redención... que... se exhaló... de la carne mortal de nuestros padres! [1892] $(I, 547)$.

Esas raíces semánticas tiene la expresión central de la composición que estudiamos; pero hay formas de mayor elaboración que están, temática y poéticamente, más cercanas. Recordemos las siguientes: ${ }^{8}$

...los héroes del 10 de Octubre...

¡Oh, sí! aquellos tiempos eran maravillosos. Ahora les tiran piedras los pedantes, y los enanos vestidos de papel se suben soibre los cadáveres de los héroes, para excomulgar a los que están continuando su obra. ¡De un revés de las sombras irritadas se vendrán abajo, si se les quieren oponer, los que tienen por única hueste las huestes de las sombras... [1889] $\{\mathbb{i}, 370)$.

Otros llegarán sin temor a la pira donde humean, como citando con la hecatombe, nuestros héroes: yo tiemblo avergonzado: tiemblo de admiración, de pesar y de impaciencia. Me parece que veo cruzar, pasando lista, una sombra colérica y sublime, la sombra de la estrella en el sombrero; y mi deber, mientras me queden pies, el deber de todos nosotros, mientras nos queden pies, es ponernos en pie, y decir: "ipresente!” [1890] (I, 376).

$\mathrm{Y}$ es lo primero este año, porque ha pasado por el aire una que otra ave de noche, proclamar que nunca fue tan vehemente ni tan tierno en nuestras almas el culto de la Revolución .... Ah, los días buenos...! ; ya me parece ver brillar el sol sobre las estatuas de los héroes, y sobre el pórtico de palmas de mármol! [1891] (I, 384-289).

8 Los párrafos citados se han tomado de discusiones conmemorativas de la Guerra de los Diez Años. 
Tales son los ingredientes y hasta la trabazón de ideas del poema XLV. Si la imagen central, o su expresión más sintética, no se halla presente, había salido ya, sin embargo, de la pluma de Martí, antes de que pronunciara los discursos anteriores. En 1888, en artículo titulado "Céspedes y Agramonte", se encuentra, al final de un párrafo sobre el primero, en los términos siguientes: "En tanto, isé bendito, hombre de mármol!" $(\mathrm{I}, 516) \mathrm{Y}$ su forma definitiva estará representada por una dedicatoria cuya fecha desconocemos, pero que consideramos posterior, en la que la idea, ya ampliada como en el poema, encierra a todos los héroes de la Guerra Grande. Dice así: "A Fernando López de Queraltáa, que peleó con los hombres de mármol. Su amigo envidioso. José Martí." ${ }^{9}$

Sin el conocimiento de las citas que preceden no es posible captar toda la emoción patriótica, toda la angustia cívica que inspiran al autor. Contra timoratos y desleales, para hombres de frente alta y espíritu decidido se escribió el poema.

¿Es que Martí trata o madura sus imágenes en la prosa antes de llevarlos al verso? Temeridad sería una respuesta afirmativa al respecto cuando los fragmentos citados en este trabajo no confirman tal cosa. Aunque con frecuencia el tópico metafórico surge en la prosa oratoria o epistolar, no es siempre así. $\mathrm{Ni}$, por otra parte, el verso es invariablemente, el fin de la jornada. Para el lírico insomne que había en Martí el proceso de la creación poética no podía ser sino obra incesante de creación o recreación. Y el medio de expresión literaria, si no completamente indiferente, había de resultar al menos bastante secundario. Sí puede hablarse de temas e imágenes favoritos, o relacionados con ciertas experiencias emocionales, que el escritor trabaja y renueva a cada recurrencia de su estímulo. De ahí ese paralelismo, ese trasiego como de vasos comunicantes, entre prosa y verso. Lo que igualmente queda como hecho incontrovertible es la intensidad y claridad poco usual con que su obra toda, y en particular su producción poética, va surgiendo como resonancia lírica de la existencia cotidiana. En Martí, más que en otro autor alguno, la poesía es constante autobio-

9 "Una carta de Néstor Carbonell a Lizaso", El mundo (La Habana), septiembre 13, 1949. López de Queralta fue veterano de la Guerra de los Diez Años. 
grafía espiritual que, paradójicamente, se abraza más a la vida cotidiana a medida que el hombre se aproxima más a la muerte. Hay en ella una evidente urgencia de confesión personalísima que se acentúa y diafaniza con los años. De modo que el torrente de visiones singulares, tumultuosas, de la juventud, desemboca al fin en los Versos sencillos, remanso como de síntesis y recuento de grandes dolores y grandes esperanzas.

Otto Olivera

Syracuse University 